\title{
Modeling the climate effects of different subregional uplifts within the Himalaya-Tibetan Plateau on Asian summer monsoon evolution
}

\author{
ZHANG Ran ${ }^{1 *}$, JIANG DaBang $^{1,2,3}$, LIU XiaoDong $^{4}$ \& TIAN ZhiPing ${ }^{2,5}$ \\ ${ }^{1}$ Climate Change Research Center, Chinese Academy of Sciences, Beijing 100029, China; \\ ${ }^{2}$ Nansen-Zhu International Research Centre, Institute of Atmospheric Physics, Chinese Academy of Sciences, Beijing 100029, China; \\ ${ }^{3}$ Key Laboratory of Regional Climate-Environment Research for Temperate East Asia, Chinese Academy of Sciences, Beijing 100029, China; \\ ${ }^{4}$ State Key Laboratory of Loess and Quaternary Geology, Institute of Earth Environment, Chinese Academy of Sciences, Xi'an 710075, China; \\ ${ }^{5}$ Graduate University of Chinese Academy of Sciences, Beijing 100049, China
}

Received December 22, 2011; accepted April 23, 2012; published online June 17, 2012

\begin{abstract}
Considering the different uplifting time of different subregions of the Himalaya-Tibetan Plateau (TP), a series of numerical simulations have been conducted with the Community Atmosphere Model (CAM4) developed at the National Center for Atmospheric Research to explore the effects of the phased tectonic uplift of the Himalaya-TP on the evolution of Asian summer monsoons. The results show that the uplifts of the Himalaya and northern TP significantly affect the evolutions of South Asian summer monsoon and northern East Asian summer monsoon respectively. That is, the tectonic uplift of the Himalaya intensifies the South Asian summer monsoon circulation and increases the precipitation in South Asia, whereas the uplift of the northern TP intensifies the northern East Asian summer monsoon circulation and increases the precipitation in northern East Asia. Compared with previous simulations, current comparative analyses of modeling results for different subregional uplifts within the Himalaya-TP help deepen our understanding of the evolutionary history of Asian monsoons.
\end{abstract}

Himalaya-Tibetan Plateau, tectonic uplift, Asian summer monsoon, numerical simulation

Citation: Zhang R, Jiang D B, Liu X D, et al. Modeling the climate effects of different subregional uplifts within the Himalaya-Tibetan Plateau on Asian summer monsoon evolution. Chin Sci Bull, 2012, 57: 4617-4626, doi: 10.1007/s11434-012-5284-y

The Tibetan Plateau (TP), which has been treated as the world's "third pole", has a significant influence on Asian and global climate change. Its impact on the Asian monsoon climate mainly manifests in thermodynamic and dynamic aspects. The uplift of the TP has remarkable climatic and environmental effects, and it has important effects on the formation and evolution of Asian monsoons [1-3]. The climatic effects of the TP uplift have been a hot issue in paleoclimate research field for many years. The tectonic uplift history of the Himalaya-TP and the climatic effects of the uplift process are two important research contents, and solving them will deepen our understanding of the evolutionary history of Asian monsoons.

For the tectonic uplift history of the Himalaya-TP, the uplift of the Himalaya-TP is generally viewed as a stepwise

*Corresponding author (email: ranzhg@gmail.com) rising process [4]. Many studies have referred to the uplift history among the different subregions of the Himalaya-TP. The central-southern TP had probably approached to a quite high height before the Miocene [5,6]. The Himalaya also might have uplifted to a considerable height before the Pliocene [7-9]. The periods of significant tectonic activities and uplift/growth events in the northern TP mainly occurred in the late Miocene and Pliocene [10-15]. The crustal deformation propagates from the Himalayan collision front to the north on the geological time scale, and the tectonic age in the northern regions is younger than that in the southern regions. Thus, the uplift time is different among the central-southern TP, the Himalaya region and the northern TP. Debates are ongoing about the exact uplift time. However, these evidences above indicate that the central-southern TP uplifted first, then the Himalayan region uplifted, and the 
northern TP uplifted last. These works help us to further understand the uplift history of the Himalaya-TP [6].

Regarding the climatic effect of the TP uplift, several numerical studies [16-18] have shown that the uplift of the Himalaya-TP had a significant influence on the development and evolution of Asian monsoons, and the aridity of Central Asia has gradually intensified with the TP uplift [19]. The climatic effects of the TP uplift changed little when used global coupled ocean-atmosphere models [18,20] or the boundary conditions of the Pliocene [21]. An et al. [16] reported that only when the central TP uplifted with a large scale and developed westward, the precipitation of India increased significantly. Later research [22] showed that the topography of Asia west of $80^{\circ} \mathrm{E}$ had more significant effects on the Indian summer monsoon precipitation than the topography of Asia east of $80^{\circ} \mathrm{E}$. Moreover, the East Asian monsoon might be more sensitive to the TP uplift than the South Asian monsoon [17]. The uplift of the northern TP mainly resulted in an intensified summer monsoon and increased precipitation in northern East Asia, but it had little influence on the South Asian monsoon [23]. Provided that the narrow orography of the Himalayas and adjacent mountain ranges are reserved, the simulated lowlevel wind, precipitation and thermodynamic structure of large-scale Indian monsoon are nearly unaffected by the removal of the TP [24]. These findings show that the climatic effects of the plateau uplift were different among different subregions of the Himalaya-TP.

The earlier numerical simulations on the TP uplift mostly used similar experimental design. They carried out the simulations with a linearly increasing topographic height, either in the region of the TP alone or globally. Although this experimental design can be helpful to understand the mechanism of how topography influences the monsoon system, this approach is inconsistent with the geological records of the Himalaya-TP phased uplift. These experimental designs do not reflect the real conditions occurring in the geologic history, so some uncertainties remain about the results, and these uncertainties further hamper our understanding about the climatic effect of the TP uplift. In this paper, based on the different uplift time of some important parts of the Himalaya-TP, we design a series of numerical experiments to examine the influence of the main phased uplift of the Himalaya-TP on the development of the Asian monsoon and aridity in the Central Asia. A comparative analysis is performed on the climatic effects of the phased uplift among the different subregions of the Himalaya-TP, and we further discuss the effect of the Himalaya-TP phased uplift combining with the evolutional history of Asian monsoon.

\section{Model introduction and experimental design}

\subsection{Model introduction}

The model used here is the National Center for Atmospheric
Research Community Atmosphere Model version 4 (CAM4), which is the seventh generation of the global general circulation model. Compared with CAM3, many parts have been changed for CAM4. For example, the core is changed from the spectral core used in CAM3 to the finite volume core in CAM4, and the effects of deep convection are included in the momentum equation. For detailed information about CAM4, please refer to Gent et al. [25]. Moreover, the land module Community Land Model version 4 (CLM4) is also used, and the ability of this model to simulate the land surface climate was evaluated in Lawrence et al. [26]. The horizontal resolution of CAM4 used here is $2^{\circ}$, which is configured for $1.9^{\circ}$ in longitude and $2.5^{\circ}$ in latitude. CAM4 uses 26 vertical layers. CLM4 and CAM4 use the same horizontal resolution, and multiple land surface types and plant function types can be contained within one grid. Here, we prescribe the modern climatologically averaged sea surface temperature and sea ice cover as the oceanic boundary conditions in our experiments, and emphatically analyze the response of summer atmospheric circulation and precipitation to the phased uplift of the plateau.

\subsection{Experimental design}

As described earlier, the uplifts of the central-southern TP, Himalaya and northern TP occurred at different time. To emphasize this difference, we treat each region as a single research object. Although the uplift time in the east-west direction of the TP is also different, we only consider the different uplift time in the south-north direction.

We design five numerical experiments. The topography in each experiment is shown in Figure 1. In order to be in harmony with the surrounding topography, we set the height to $600 \mathrm{~m}$ in regions where the topography is changed. With the exception of the changed topography, the other boundary conditions are the same as the preindustrial conditions in order to detect the influence of the changed topography. The first experiment lowers the topography in the whole Himalaya-TP region (NTP). Based on the NTP, the second experiment uplifts the central-southern TP (TIS, Figure 1(a)). The third experiment uplifts the Himalaya (HIM, Figure 1(b)) and also includes the uplift regions in the TIS. The fourth experiment uplifts the northern TP (TIN, Figure 1(c)) and also includes the uplift regions in the HIM. The last experiment uplifts the Mongolian Plateau (MON, Figure 1(d)) and also includes the uplift regions in the TIN. The topography in the MON is the modern topography, and we contrast the model results of the MON with the reanalysis data to evaluate the performance of the model simulation (see Section 2.1). Those five experiments can approximately represent the different tectonic uplift stages of the Himalaya-TP, and the differences in the model results between the last four experiments and the NTP reflect the climatic effects of the different tectonic uplift stages of the Himalaya-TP. 

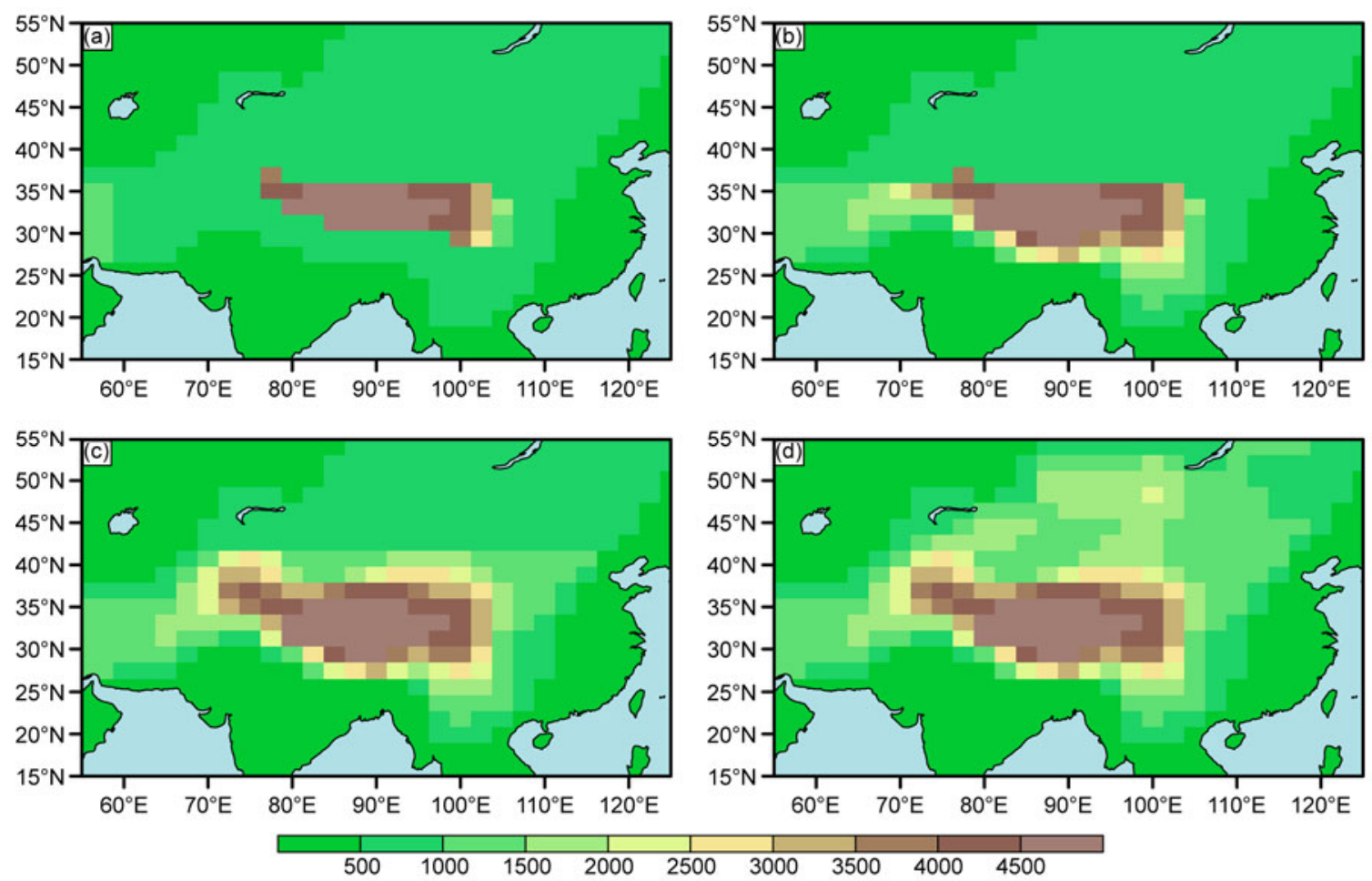

Figure 1 The Asian topography (units: m) in different numerical experiments for (a) TIS, (b) HIM, (c) TIN, and (d) MON.

Each experiment is run for 30 model years, and all reached a quasi-equilibrium state within the first 15 model years. The climatological mean is derived from the last 15 years of each experiment for analysis. We primarily investigate the response of the summer (June, July and August) atmospheric circulation and precipitation to the tectonic uplifts. Referring to previous researches [16,17], we divide the region into three research areas, the northern Asian monsoon area (NEAM, $\left.34^{\circ}-42^{\circ} \mathrm{N}, 105^{\circ}-120^{\circ} \mathrm{E}\right)$, the South Asian monsoon area $\left(\mathrm{SAM}, 5^{\circ}-25^{\circ} \mathrm{N}, 65^{\circ}-90^{\circ} \mathrm{E}\right)$ and the Central Asian area $\left(\mathrm{CA}, 42^{\circ}-50^{\circ} \mathrm{N}, 80^{\circ}-110^{\circ} \mathrm{E}\right)$, to examine changes in the regional averaged climate elements.

\section{Model results}

\subsection{Model evaluation}

To evaluate the performance of CAM4, we compare the climatologically averaged summer $850 \mathrm{hPa}$ wind field, precipitation and sea level pressure (PSL) from the MON with the climatologically averaged results of 1979-2008 from Climate Prediction Center Merged Analysis of Precipitation (CMAP) [27] and NCEP-DOE reanalysis data [28]. For a quantitative analysis, the CMAP data and reanalysis data with a horizontal resolution of $2.5^{\circ} \times 2.5^{\circ}$ are first linearly interpolated to model's horizontal resolution, and we then calculate the different statistical variables for the precipitation and PSL within the region of $0^{\circ}-60^{\circ} \mathrm{N}$ and $50^{\circ}-140^{\circ} \mathrm{E}$. For the definitions of the different statistical variables, see ref. [29].

For the reanalysis data, the airflow from the Somali jet stream, the Australian cross-equatorial flow and the southeast airflow from west of the western North Pacific Subtropical High combine in eastern China, where southerly airflow prevails. Although the model simulates a weaker Australian cross-equatorial flow and a stronger southeast airflow from the western North Pacific, the model can reproduce the main features of large-scale summer monsoon circulation (Figure 2(a),(b)). The model results show that there are strong precipitation centers near the western Indian Peninsula and southern Himalaya, and this bias widely exists in CAM4 and the earlier CAM versions [24]. The model can reasonably simulate the change of precipitation, which decreases from southern to northern China. For a quantitative analysis on precipitation, the simulated regional average (RA) value is $0.34 \mathrm{~mm} / \mathrm{d}$ higher than the CMAP data. The spatial correlation coefficient (SCC) is 0.51 . The ratio of the standard deviation (RSD) is 1.08 , and the difference between the root mean square error (RMSE) and the RMSE excluding systematic model errors (RMSE2) is $0.01 \mathrm{~mm} / \mathrm{d}$, showing that some biases remain in simulating the precipitation in the research areas. Upon comparison with other models [30], CAM4 can reasonably simulate the Asian precipitation.

For PSL, though some details are still imperfect, the model can better simulate the spatial configuration between the thermal low pressure in the Asian continent and the subtropical high over the western North pacific (Figure 2(c),(d)). 

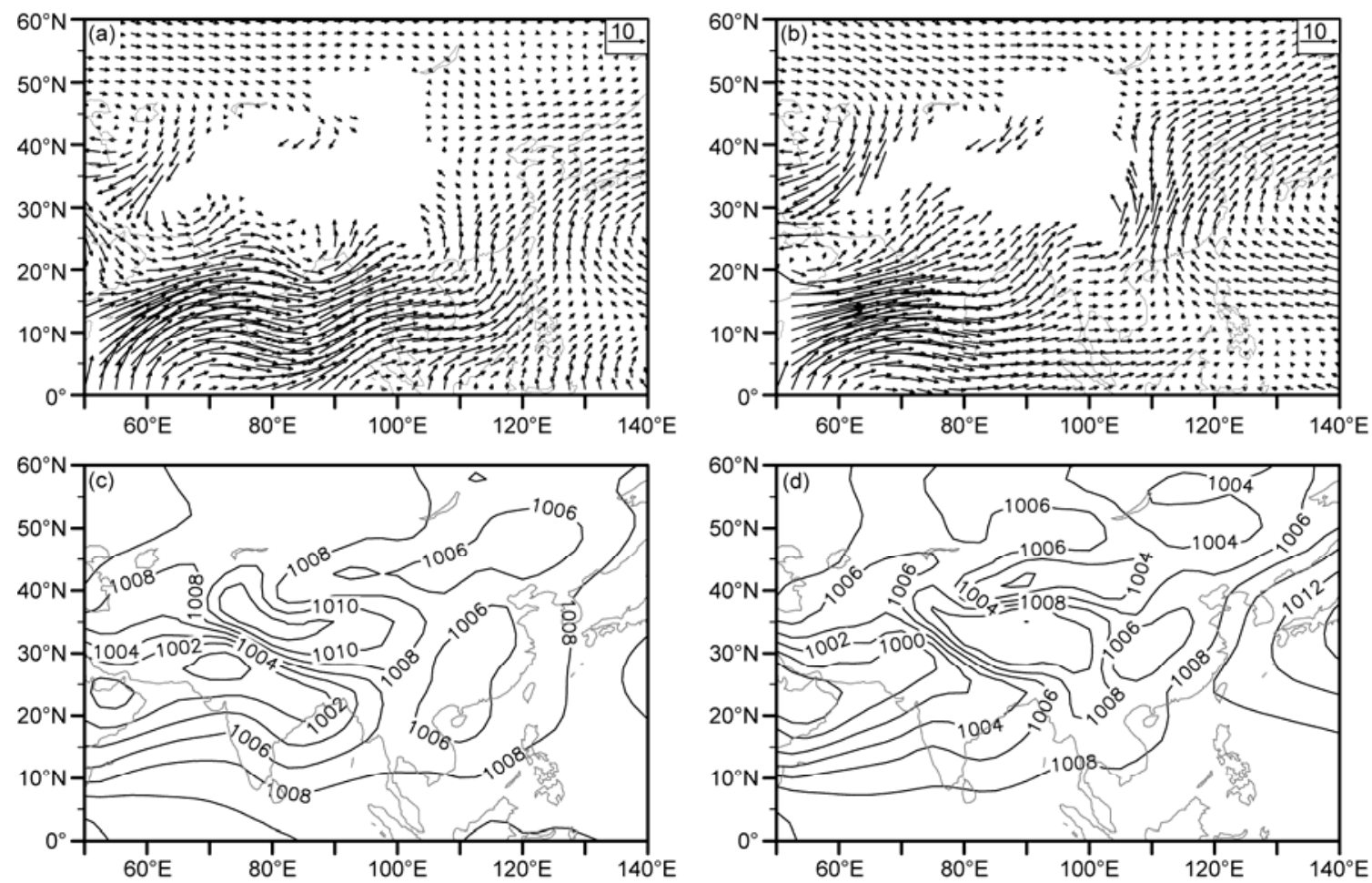

Figure 2 1979-2008 climatologically averaged values from the NCEP-DOE reanalysis data ((a), (c)) and the model results from the MON ((b), (d)). (a) and (b) are summer $850 \mathrm{hPa}$ wind field (units: $\mathrm{m} / \mathrm{s}$ ). The areas where the height is greater than $1500 \mathrm{~m}$ are left blank. (c) and (d) are sea surface pressure, with nine-point local smoothing (units: $\mathrm{hPa}$, contour interval is $2 \mathrm{hPa}$ ).

The simulated RA is $0.62 \mathrm{hPa}$ lower than the reanalysis data, and the SCC is 0.78 , indicating that the model can well capture the overall features of the PSL spatial distribution. The RSD is 1.22 , and the difference between the RMSE and RMSE2 is $0.09 \mathrm{hPa}$, meaning that the systematic model errors are relatively small. In summary, the model can adequately simulate the spatial pattern of $850 \mathrm{hPa}$ wind field, precipitation and PSL, and it can reasonably simulate the Asian large-scale summer monsoon climate.

\section{$2.2850 \mathrm{hPa}$ wind field change}

The different uplift stages of the Himalaya-TP have important effects on the $850 \mathrm{hPa}$ wind field change. From the $850 \mathrm{hPa}$ wind field figures with and without the HimalayaTP topography (data not shown), a weak southerly wind exists in the summer in eastern Asia before the uplift of the plateau, which relates to the land-sea thermal contrast and mesoscale topography. After uplifting, the Himalaya-TP is a strong heat source, which strengthens the continent thermal low pressure and has remarkable effects on South Asian and East Asian summer monsoon circulation, with the westerly winds in the northern Arabian Sea and Indian Peninsula and the southerly wind in East Asian remarkably strengthened.

The influences of different phased uplifts of the Himalaya-TP on the surrounding atmospheric general circulation are significantly different (Figure 3). After the uplift of the central-southern TP (Figure 3(a)), due to the heat source effects, cyclonic circulation anomalies exist in the vicinity of the uplifted region, strengthening the westerly wind in the northern Indian Peninsula. After the uplift of the Himalaya (Figure 3(b)), the atmospheric circulation anomalies are further developed. In the west of the uplifted area, the southward wind anomalies from inland region weaken obviously. In addition, the northward monsoon circulation in southern East Asia and the westerly wind in northern Arabian Sea significantly strengthen. The uplifts of the northern TP and Mongolian Plateau (Figures 3(c),(d)) mainly affect the East Asian monsoon, obviously strengthening the wind from the western Pacific, except strengthening the southward wind in west of the TP.

The effects of the Himalaya and northern TP uplifts on summer atmospheric circulation are obviously different (Figure 4). After the Himalaya uplifts (Figure 4(a)), the westerly wind anomalies in the northern Arabian Sea strengthen distinctly, and the subsequent uplift has little effect on the westerly wind anomalies in this region. In contrast, the uplift of the northern TP significantly strengthens the East Asian summer monsoon circulation, particularly strengthening the wind from the western Pacific (Figure 4(b)). The summer geopotential height field at $500 \mathrm{hPa}$ also shows that the contour of $5880 \mathrm{gpm}$ appears after the northern TP uplifts (Figure 5), and this approaches the contour's distribution after the Mongolian Plateau uplifts. This finding indicates 

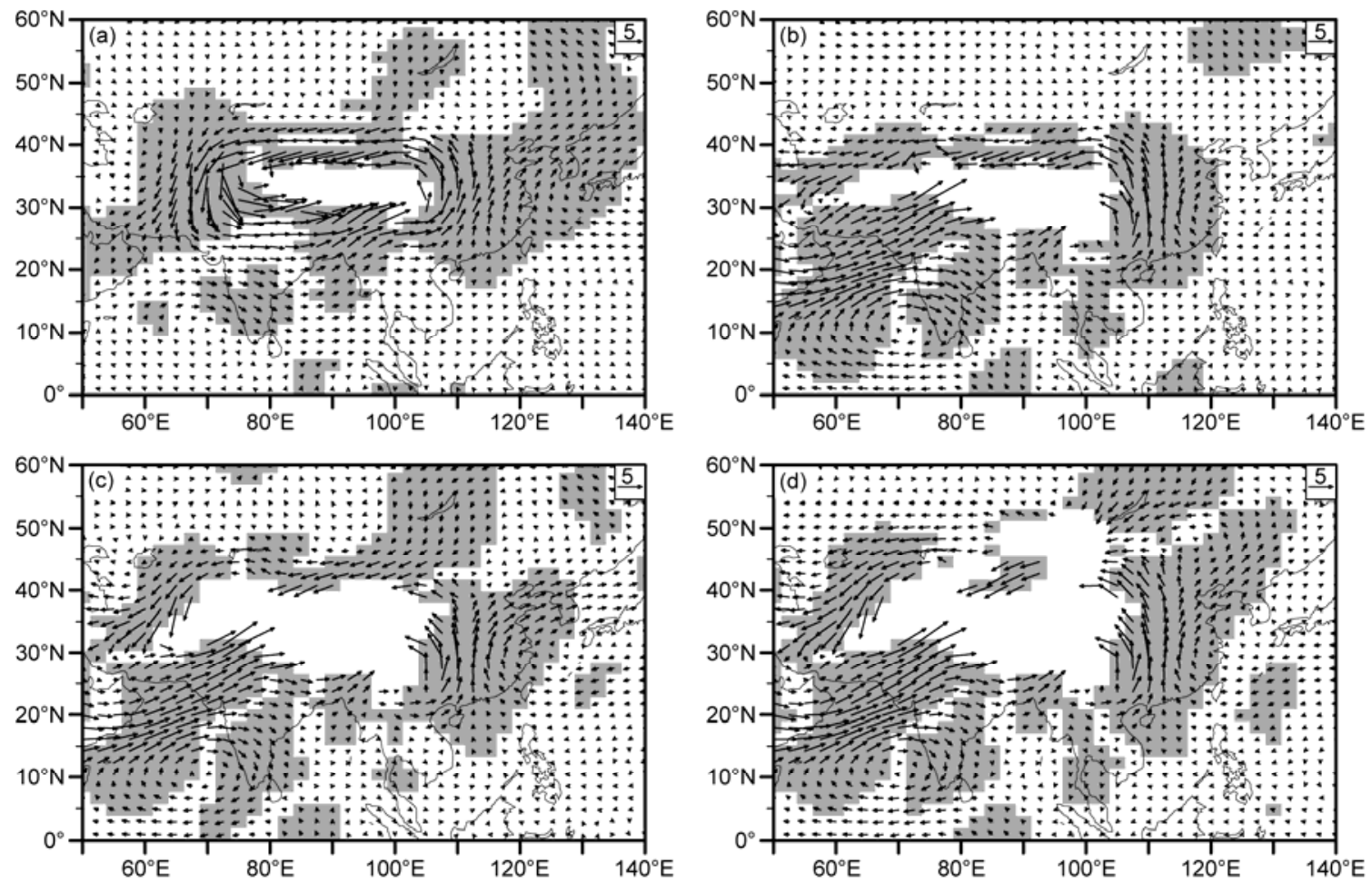

Figure 3 The summer-averaged $850 \mathrm{hPa}$ wind field change (units: $\mathrm{m} / \mathrm{s}$ ) between different experiments for (a) TIS-NTP, (b) HIM-NTP, (c) TIN-NTP, and (d) MON-NTP. The areas with confidence levels larger than 95\% using Student's $t$-test are shaded, and the areas where the height is greater than $1500 \mathrm{~m}$ are left blank.
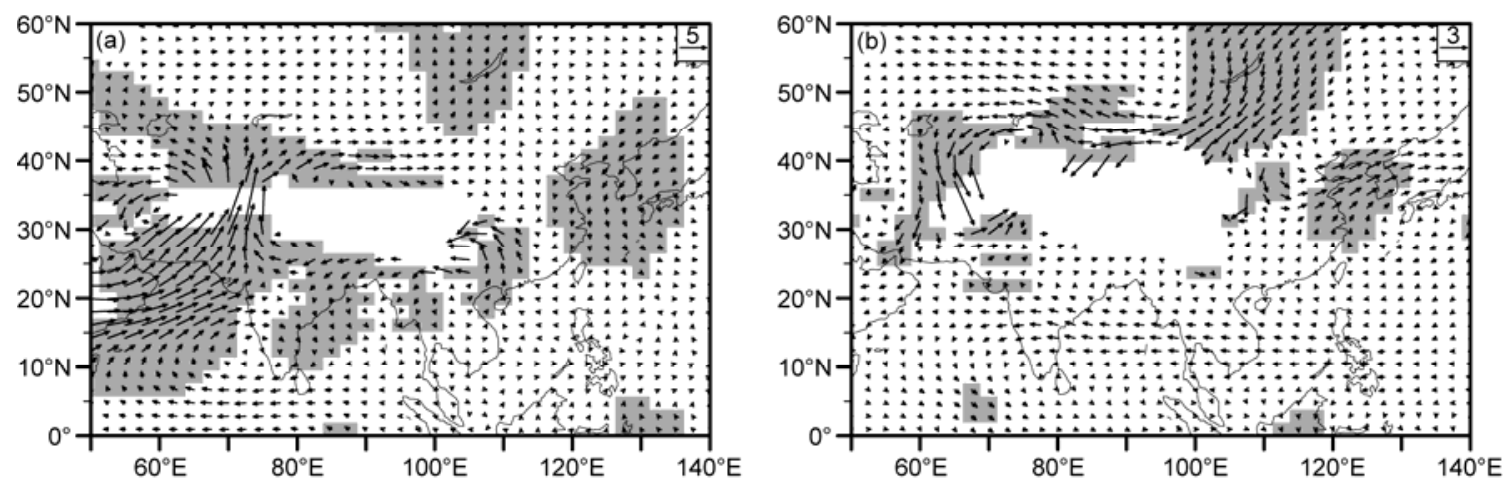

Figure 4 The summer-averaged $850 \mathrm{hPa}$ wind field change (units: $\mathrm{m} / \mathrm{s}$ ) between different experiments for (a) HIM-TIS and (b) TIN-HIM. See Figure 3 for details.

that the western North Pacific subtropical high also strengthens obviously after the northern TP uplifts.

\subsection{Precipitation change}

The differences in the climatic effects of the different Himalaya-TP subregions can also be found in the precipitation changes. From the summer precipitation figures with and without the Himalaya-TP topography (data not shown), when the plateau has not uplifted, the precipitation mainly occurs in the western Indian Peninsula. After uplifting, precipitation increases more in the regions near the western and eastern Indian Peninsula and southern Himalaya. The dif- ferent uplift stages of the Himalaya-TP also have different effects on regional precipitation (Figure 6). After the central-southern TP uplifts (Figure 6(a)), the precipitation in the vicinity of the uplifted regions decreases remarkably, and the dry airflow, flowing from inland regions to northern India, weakens the regional precipitation formation (Figure 3(a)) [22]. After the Himalaya uplifts (Figure 6(b)), the scope of areas with increased (decreased) precipitation expands (narrows) in South Asia, corresponding to the strengthened westerly wind circulation in the northern Arabian Sea (Figure 3(b)). Moreover, the northern TP uplift (Figure 6(c)) notably increases the precipitation in northern East Asia, which is consistent with the strengthened summer 

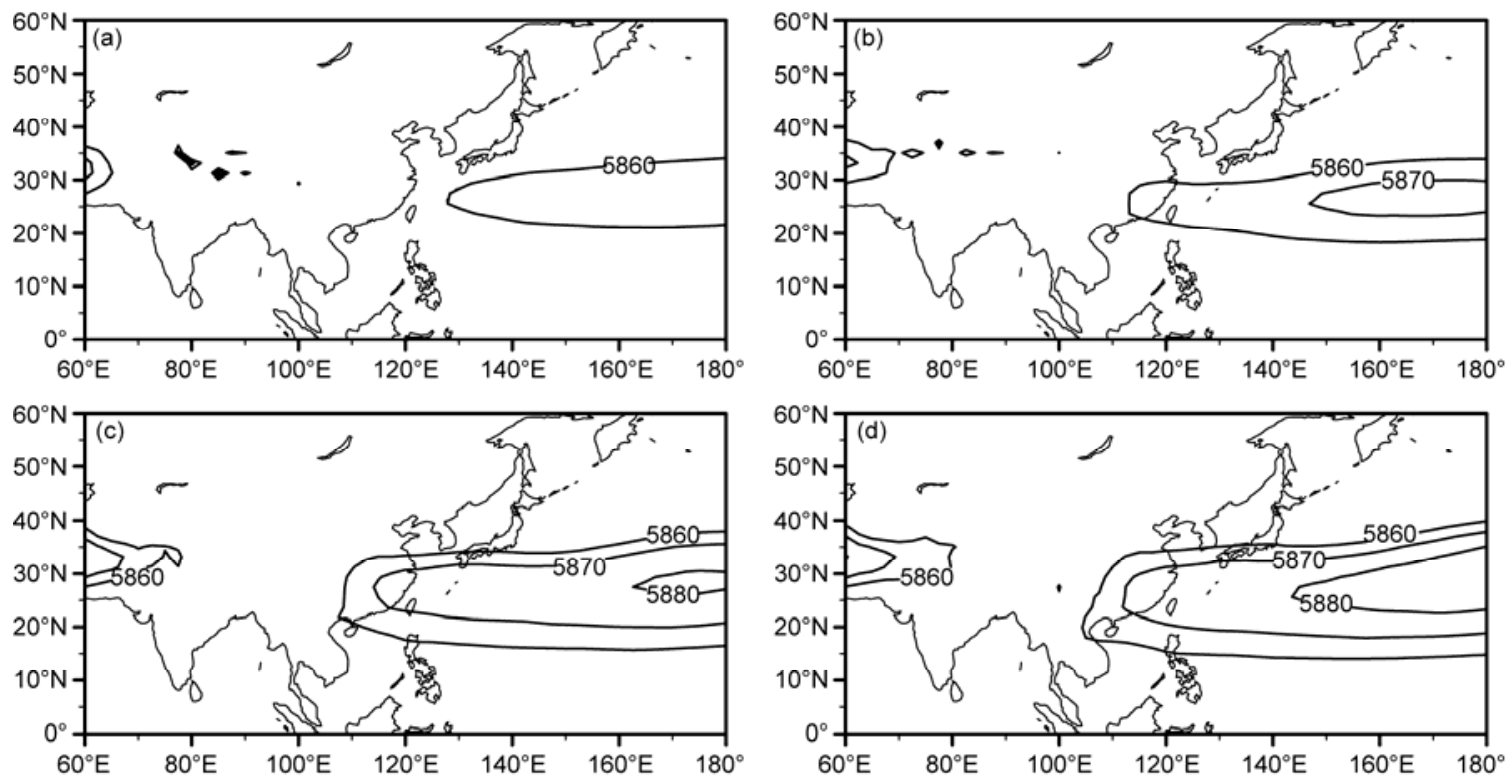

Figure 5 The summer-averaged $500 \mathrm{hPa}$ geopotential height (units: gpm) in different experiments for (a) TIS, (b) HIM, (c) TIN, and (d) MON. The geopotential height contours greater than $5860 \mathrm{gpm}$ are shown, and the contour interval is $10 \mathrm{gpm}$.
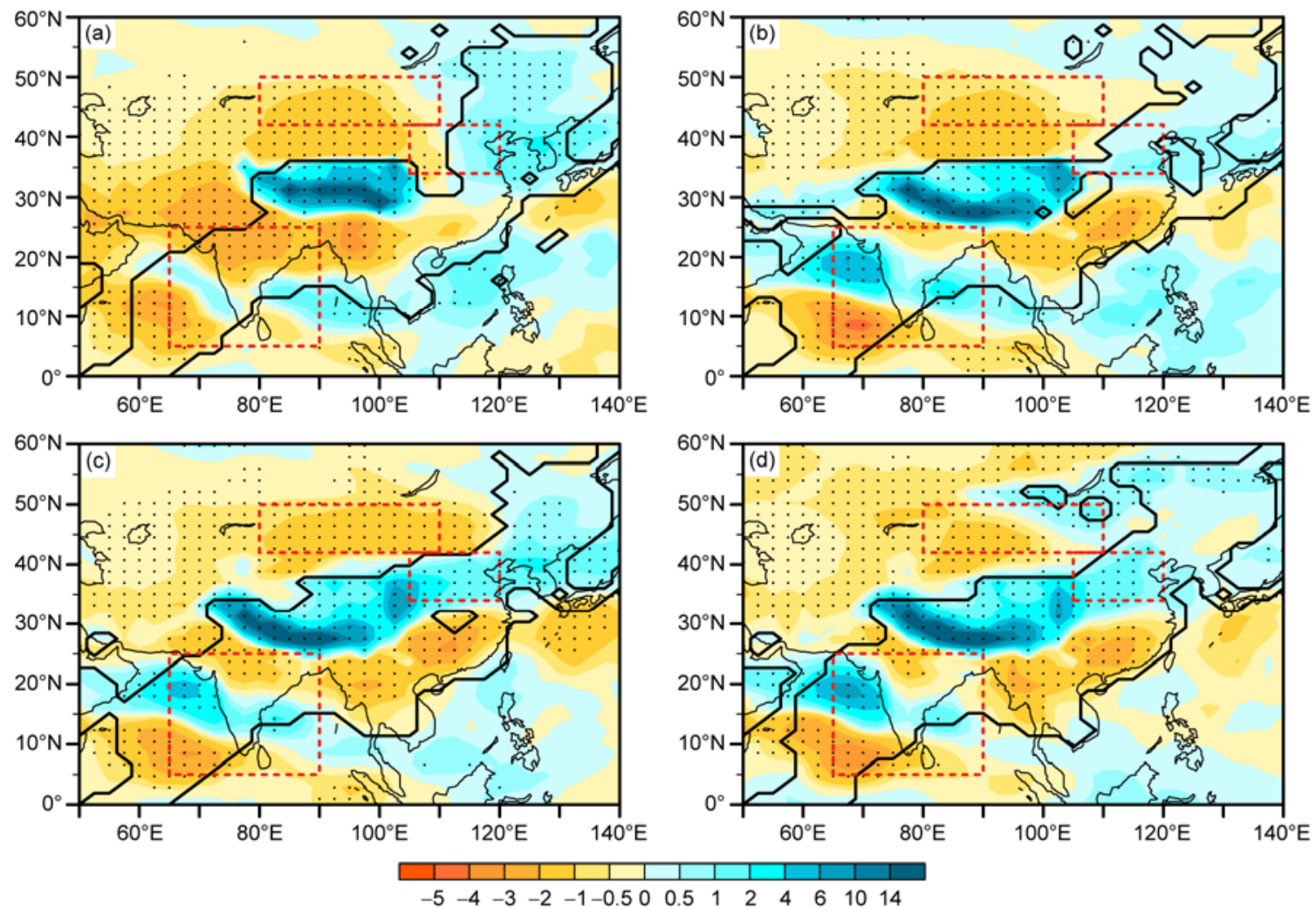

Figure 6 The summer-averaged precipitation change (units: mm/d) between different experiments for (a) TIS-NTP, (b) HIM-NTP, (c) TIN-NTP, and (d) MON-NTP. The areas with confidence levels larger than 95\% using Student's $t$-test are dotted. Thick black line represents the boundaries of the modeled monsoon region for (a) TIS, (b) HIM, (c) TIN, and (d) MON. The red dashed-line boxes are the monsoon areas and the Central Asian area defined in this article.

monsoon circulation from the western Pacific (Figure 4(b)).

In contrast to the precipitation change of the Himalaya and northern TP uplifts, the Himalaya uplift can induce a distinct precipitation increase in South Asia, with the max- imum value occurring in the northeastern Arabian Sea, while the northern TP uplift significantly increases the precipitation in northern East Asia (Figure 6).

To define monsoon regions, we use the criteria of Zhang 
and Wang [31], who classified a monsoon region when (1) precipitation during summer (from May to September, MJJAS) is equal to or greater than $3 \mathrm{~mm} / \mathrm{d}$ and (2) the ratio of summer to annual precipitation is greater than $55 \%$. Based on modern observations, this method compares well with previous definitions of the regional monsoons [31]. After the uplift of the central-southern TP (Figure 6(a)), there are monsoon regions in both East Asia and South Asia, but the scope is smaller than the modern one (Figure 6(d)), and the reduced regions are mainly located in South Asia and northern East Asia. After the Himalaya uplifts, the scope of the South Asian monsoon regions grows and approaches the modern one, but the scope of northern East Asian monsoon regions still differs much from the modern one. After the northern TP uplifts, the scope of northern East Asian monsoon regions finally approaches the modern one.

For further analyzing and summarizing the precipitation changes in Asian monsoon regions and Central Asia, the precipitation in NEAM, SAM and CA is averaged and discussed below. Figure 7 shows the summer and annual averaged precipitation change, respectively. For summer, the uplift of the central-southern TP can slightly increase the precipitation in NEAM, but it decreases the precipitation in SAM and CA. After the uplift of the Himalaya, the precipitation in SAM increases significantly. The uplift of northern TP increases the precipitation in NEAM, accompanied by the decreased precipitation in CA. The uplift of the Mongolian Plateau increases the precipitation in CA and decreases the precipitation in NEAM. The pattern of annual precipitation change is similar to the summer pattern in every uplift stage, but with smaller magnitudes. The main feature is that the uplift of the Himalaya (northern TP) has a significant influence on the precipitation in SAM (NEAM).

\section{Discussion and conclusions}

\subsection{Differences in climatic effects among the uplifts of the different Himalaya-TP subregions}

Summarizing the changes of the $850 \mathrm{hPa}$ wind field, precip- itation and the scope of the Asian monsoon area from every uplift stage, we find that the uplift of the Himalaya (northern TP) has a significant influence on the South Asian (northern East Asian) summer monsoon climate. The model results mainly show that, after the uplift of the Himalaya, the precipitation in South Asia increases, and the westerly wind in northern Arabian Sea strengthens, while the South Asian monsoon area is shown to be very close to the modern one, indicating that the South Asian summer monsoon circulation strengthens significantly, which confirms previous work about the significant influence of the Himalaya on the South Asian summer monsoon climate [24]. The uplift of the northern TP mainly increases the precipitation in northern East Asia and strengthens the East Asian summer monsoon circulation, which is quite different from the circulation characteristics before the northern TP uplifts.

The uplift of the central-southern TP has important effects on different regional precipitation, such as the decreased effects on the summer precipitation in SAM and CA. For CA, the influence of the central-southern TP uplift is more significant than the subsequent uplift stage. The northern TP uplift makes the precipitation in CA decrease more, while the uplift of the Mongolian Plateau increases the precipitation in CA, which indicates that the uplifts of the centralsouthern TP and northern TP have significant effects on the intensified drought in CA. The model results show that the uplifts decrease the summer precipitation for southern East Asia (Figure 6). This finding is related to the modeled precipitation bias in the MON in this region, where the simulated precipitation is obviously smaller than the CMAP data.

We performed a comparative analysis on the climatic effects of the uplifts among different subregions of the Himalaya-TP. Supporting the previous model results, the present simulations show that the tectonic uplifts have important effects on the regional climate. We further confirm that the existence of the plateau promotes the development of the East Asian monsoon climate and the drought of Central Asia. We also find that the extent of its effect is directly related to the uplifted region, and the climatic effects of the uplifts are quite different among the subregions, which
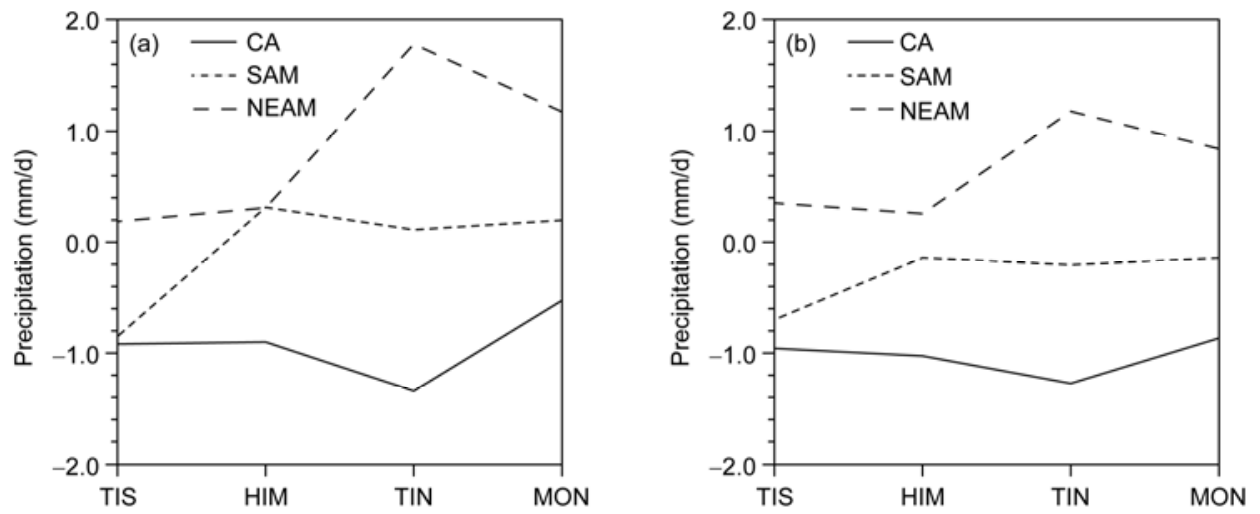

Figure 7 The regional precipitation changes between the four experiments and the NTP for (a) summer and (b) annual averages. 
cannot be directly found in previous simulations with a linearly increasing height of topography. Moreover, because of the ideal experimental design in the previous simulations, the corresponding conclusions may need more experiments to be confirmed [32]. For example, the results shown in previous work [18], with the plateau height below $60 \%$ of its current height, the southwesterly monsoon flow from the Indian Ocean becomes strong by uplift and transports moisture toward East Asia. With higher mountains, the intensified subtropical trade winds transport moisture from the Pacific into the Asian continent. Thus, $60 \%$ of the current height is treated as a threshold value for East Asian monsoon onset or development [18]. The present model results show that the intensified South Asian summer monsoon is induced by the Himalaya uplift, while the intensified East Asian summer monsoon can be attributed to the uplift of the northern TP. When the uplift time of the subregions of the Himalaya-TP differs greatly, it is possibly more closely to the actual earth history that attributing the intensification of Asian summer monsoon subsystem to the uplifts of different subregions.

\subsection{Asian monsoon evolutionary history and phased Himalaya-TP's uplift}

The East Asian climate history during the Neogene has been studied for a long time, but some disputes remain over the question of when the East Asian monsoon was established. One view holds that the East Asian monsoon began in the late period of the late Miocene, approximately 7-8 Ma [33-35]. East Asia was generally uniformly humid before the late middle Miocene, and this was replaced by a mid-latitude arid belt from the late middle Miocene into the earlier part of the late Miocene [34]. Northern China became more humid from the time of the onset of red clay deposition approximately 7-8 Ma [33]. Another view holds that the beginning of the East Asian monsoon is much earlier, in the late Oligocene to early Miocene [36-40]. The central-southern TP might have uplifted and approached a great height before the Miocene [5,6], which is related to the climate events that occurred in the late Oligocene to early Miocene [41]. The model results demonstrate that the uplift of the central-southern TP can increase the summer and annual precipitation in NEAM. After the uplift of the central-southern TP, the East Asian climate has already been the monsoon climate, which is qualitatively consistent with geological records [41]. However, the scope of the northern East Asian monsoon area is limited, which gradually grows with the subsequent phased uplift of the Himalaya-TP (Figure 6). The time of the onset of red clay deposition approximately 7-8 Ma is probably the earliest whole uplift time of the northern TP. Our model results show that the uplift of the northern TP has significant effects on the increase of the summer and annual precipitation in NEAM and the scope of the monsoon region is very close to the modern one after the uplift of the northern TP. Thus, the uplift of the northern TP has important effects on the evolution of the monsoon climate in northern East Asia, and it becomes the key factor to study the East Asian climate change in the late Miocene and middle Pliocene [42,43]. Thus, the change of the East Asian climate may have a close relationship with the phased TP uplift in the two disputable periods about when the East Asian monsoon began to establish. Because of not considering other factors, such as the Paratethys Sea retreat [44] and land-sea distribution change [45-47], we can not give a deeply discussion about the onset time of East Asian monsoon.

The Himalaya might have uplifted to a considerable height before the Pliocene [8,9], and the climatic effects of the uplift probably corresponded to the climate events in approximately 10-8 Ma [16]. Quade et al. [48] reported abrupt changes in $\delta^{13} \mathrm{C}$ and $\delta^{18} \mathrm{O}$ values in pedogenic carbonates from northern Pakistan between 10-6 Ma. Garzione et al. [49] noted that a thinning of forests and an expansion of grasslands along the Himalaya occurred at $\sim 11$ $\mathrm{Ma}$, and changes in the architecture of sediment deposited on the plains of northern India were related to increased flooding near $10 \mathrm{Ma}$, which might reflect an increased frequency of strong monsoon rains [50]. Besides, planktonic foraminifer became abundant near $10 \mathrm{Ma}$, which was derived from deep-ocean drilling in the western Arabian Sea. These findings suggest an onset or strengthening of the South Asian monsoon at that time [16]. The model results show that the SAM precipitation increases significantly after the uplift of the Himalaya, and the westerly wind in northern Arabian Sea strengthens, indicating that the South Asian monsoon strengthens significantly. Moreover, the subsequent uplift has little effect on the SAM precipitation and westerly wind change. The qualitative consistency between the model results and the geological records [16] indicates that the uplift of the Himalaya has important effects on South Asian climate evolution.

Detailed magnetostratigraphy of a $4.5 \mathrm{~km}$ section near Yecheng in the western Kunlun Mountains showed that the change from deposition on distal alluvial plains to proximal alluvial fans occurred beginning at $4.5 \mathrm{Ma}$ [10]. The Qilian Mountain raised at $\sim 5.3 \mathrm{Ma}[11]$ and began to entirely and rapidly raise at $\sim 3.6 \mathrm{Ma}$. Sun et al. [13] suggested that the late Cenozoic tectonic deformation, marked by folding and thrusting, occurred at $\sim 5.3 \mathrm{Ma}$. All of the above show that the drastic uplift of the northern TP mainly occurred during the late Miocene and Pliocene. The climatic effects of the uplift can be reflected in the climate events that occurred at 3.6 Ma. Based on records of Aeolian sediments from China and marine sediments from the Indian and North Pacific oceans, An et al. [16] reported that the East Asian summer monsoon intensified and the aridity in the Asian interior enhanced in about 3.6-2.6 Ma. Zheng et al. [51] considered that the enhanced aridity in the Asian interior and the intensified East Asian monsoon at $\sim 3.6 \mathrm{Ma}$ were related to the 
rapid uplift of the TP at this time. Besides, many indices from South China Sea deep-sea record, including geochemistry, micropaleontology, pollen and so on, indicated that the East Asian monsoon underwent important evolution events at $\sim 3.2 \mathrm{Ma}$ [52]. The model results show that the uplift of the northern TP intensifies the East Asian summer monsoon and decreases the precipitation in CA, which is qualitatively consistent with the geological records [53], indicating that the uplift of the northern TP has important effects on East Asian monsoon climate evolution. It is noteworthy that the uplift of the Mongolian Plateau makes the precipitation in $\mathrm{CA}$ increase, which demonstrates that the precipitation change in CA is related to the uplift of specific region and not all phased tectonic uplift can enhance the aridity in CA.

\subsection{Simulation uncertainties}

First, we discuss the effects of the phased Himalaya-TP's tectonic uplift on the evolution of the Asian summer monsoon in this study. The phased tectonic uplift mode needs more support from geological evidence. Strengthening the understanding of the climatic effects of different subregional uplifts within the Himalaya-TP through sensitive simulations is our main purpose. To reduce model-dependent uncertainties, the model results here need more support from other models' simulations. Second, except for the topography, we keep all of the other boundary conditions unchanged. Earth's orbital parameters and the atmospheric $\mathrm{CO}_{2}$ concentration are the same as the present day values, although those boundary conditions change over time. This method isolates and highlights the effects of topography change. Lastly, the response of ocean and vegetation components to the phased tectonic uplift needs to be investigated further, and we will assess these factors in our future work.

The authors thank the two anonymous reviewers for suggestions that improved this paper. This work was supported by the National Basic Research Program of China (2009CB421407), the Knowledge Innovation Program of the Chinese Academy of Sciences (KZCX2-EW-QN202), and the National Natural Science Foundation of China (40975050, 41175072 and 40825008).

1 Li J J, Fang X M. Uplift of the Tibetan Plateau and environmental changes. Chin Sci Bull, 1999, 44: 2117-2124

2 Wang P X. Global monsoon in a geological perspective. Chin Sci Bull, 2009, 5: 1113-1136

3 Molnar P, Boos W R, Battisti D S. Orographic controls on climate and paleoclimate of Asia: Thermal and mechanical roles for the Tibetan Plateau. Annu Rev Earth Planet Sci, 2010, 38: 77-102

4 Tapponnier $\mathrm{P}, \mathrm{Xu} \mathrm{Z}$, Francoise R, et al. Oblique stepwise rise and growth of the Tibet Plateau. Science, 2001, 294: 1671-1677

5 Coleman M, Hodges K. Evidence for Tibetan Plateau uplift before 14 Myr ago from a new minimum age for east-west extension. Nature, 1995, 374: 49-52

6 Wang C S, Zhao X, Liu Z, et al. Constraints on the early uplift history of the Tibetan Plateau. Proc Natl Acad Sci USA, 2008, 105: 49874992
7 France-Lanord C, Sheppard S M F, Le-Fort P. Hydrogen and oxygen isotope variations in the high Himalaya peraluminus Manaslu leucogranite: Evidence for heterogeneous sedimentary source. Geochim Cosmochim Acta, 1988, 52: 513-526

8 Garzione C N, Quade J, Decelles P G, et al. Predicting paleoelevation of Tibet and the Himalaya from $\delta^{18} \mathrm{O}$ vs. altitude gradients in meteoric water across the Nepal Himalaya. Earth Planet Sci Lett, 2000, 183: 215-229

9 Rowley D B, Pierrehumbert R T, Currie B S. A new approach to stable isotope-based paleoaltimetry: Implications for paleoaltimetry and paleohypsometry of the high Himalaya since the late Miocene. Earth Planet Sci Lett, 2001, 188: 253-268

10 Zheng H B, Powell C M, An Z S. Pliocene uplift of the northern Tibetan Plateau. Geology, 2000, 28: 715-718

11 Métivier F, Gaudemer Y, Tapponnier P, et al. Northeastward growth of the Tibetan Plateau deduced from balanced reconstruction of two depositional areas: The Qaidam and Hexi Corridor basins, China. Tectonics, 1998, 17: 823-842

12 Fang X, Zhao Z, Li J, et al. Magnetostratigraphy of the late Cenozoic Laojunmiao anticline in the northern Qilian Mountains and its implication for the northern Tibetan Plateau uplift. Sci China Ser D-Earth Sci, 2005, 48: 1040-1051

13 Sun J M, Zhang L Y, Deng C L, et al. Evidence for enhanced aridity in the Tarim Basin of China since 5.3 Ma. Quat Sci Rev, 2008, 27: 1012-1023

14 Fu K D, Gao J P, Fang X M, et al. Relationship model of sediment grain size and Tibetan Plateau uplift in middle-west parts of Qilian Mountains. Sci China Ser D-Earth Sci, 2001, 44: 210-217

15 Wang Y, Wang X, Xu Y, et al. Stable isotopes in fossil mammals, fish and shells from Kunlun Pass Basin, Tibetan Plateau: Paleo-climatic and paleo-elevation implications. Earth Planet Sci Lett, 2008, 270: 73-85

16 An Z S, Kutzbach J E, Prell W L, et al. Evolution of Asian monsoons and phased uplift of the Himalaya-Tibetan Plateau since late Miocene times. Nature, 2001, 411: 62-66

17 Liu X D, Yin Z Y. Sensitivity of East Asian monsoon climate to the uplift of the Tibetan Plateau. Palaeogeogr Palaeoclimatol Palaeoecol, 2002, 183: 223-245

18 Kitoh A. Effects of mountain uplift on East Asian summer climate investigated by a coupled atmosphere-ocean GCM. J Clim, 2004, 17: 783-802

19 Liu X D, Yin Z Y. Forms of the Tibetan Plateau uplift and regional differences of the Asian monsoon-arid environmental evolution-A modeling perspective. J Earth Environ, 2011, 2: 401-416

20 Abe M, Yasunari T, Kitoh A. Effects of large-scale orography on the coupled atmosphere-ocean system in the tropical Indian and Pacific Oceans in boreal summer. J Meteorol Soc Jpn, 2004, 82: 745-759

21 Jiang D, Ding Z L, Helge D, et al. Sensitivity of East Asian climate to the progressive uplift and expansion of the Tibetan Plateau under the mid-Pliocene boundary conditions. Adv Atm Sci, 2008, 25: 709-722

22 Chakraborty A, Nanjundiah R S, Srinivasan J. Role of Asian and African orography in Indian summer monsoon. Geophys Res Lett, 2002, 29: 1989

23 Zhang R, Liu X D. The effects of tectonic uplift on the evolution of Asian summer monsoon climate since Pliocene. Chin J Geophys, 2010, 53: 948-960

24 Boos W R, Kuang Z M. Dominant control of the South Asian monsoon by orographic insulation versus plateau heating. Nature, 2010, 463: 218-222

25 Gent P R, Danabasoglu G, Donner L J, et al. The community climate system model version 4. J Clim, 2011, 24: 4973-4991

26 Lawrence D M, Oleson K W, Flanner M G, et al. The CCSM4 land simulations, 1850-2005: Assessment of surface climate and new capabilities. J Clim, 2011, 25: 2240-2260

27 Xie P P, Arkin P A. Analyses of global monthly precipitation using gauge observations, satellite estimates, and numerical model predictions. J Clim, 1996, 9: 840-858

28 Kanamitsu M, Ebisuzaki W, Woollen J, et al. NCEP-DOE AMIP-II Reanalysis (R-2). Bull Amer Meteorol Soc, 2002, 83: 1631-1643 
29 Tian Z P, Jiang D, Zhang R, et al. Long-term climate simulation of CCSM4.0 and evaluation of its performance over East Asia and China (in Chinese). Chin J Atmos Sci, 2012, 36: doi: 10.3878/j.issn. 1006-9895.2011.11092

30 Lin J L, Weickman K M, Kiladis G N, et al. Subseasonal variability associated with Asian summer monsoon simulated by 14 IPCC AR4 coupled GCMs. J Clim, 2008, 21: 4541-4567

31 Zhang S P, Wang B. Global summer monsoon rainy seasons. Int J Climatol, 2008, 28: 1563-1578

32 Lunt D J, Flecker R, Clift P D. The impacts of Tibetan uplift on palaeoclimate proxies. In: Clift P D, Tada R, Zheng H, eds. Monsoon Evolution and Tectonics-Climate Linkage in Asia. Geol Soc Lond Spec Publ, 2010, 342: 279-291

33 Ding Z L, Xiong S F, Sun J M, et al. Pedostratigraphy and paleomagnetism of $\mathrm{a} \sim 7.0 \mathrm{Ma}$ eolian loess-red clay sequence at Lingtai, Loess Plateau, north-central China and the implications for paleomonsoon evolution. Palaeogeogr Palaeoclimatol Palaeoecol, 1999, 152: 49-66

34 Liu L P, Eronen J T, Fortelius M. Significant mid-latitude aridity in the middle Miocene of East Asia. Palaeogeogr Palaeoclimatol Palaeoecol, 2009, 279: 201-206

35 Fortelius M, Eronen J, Jernvall J, et al. Fossil mammals resolve regional patterns of Eurasian climate change over 20 million years. Evol Ecol Res, 2002, 4: 1005-1016

36 Guo Z T, Ruddiman W F, Hao Q Z, et al. Onset of Asian desertifications by $22 \mathrm{Myr}$ ago inferred from loess deposits in China. Nature, 2002, 416: 159-163

37 Sun J M, Ye J, Wu W Y, et al. Late Oligocene-Miocene mid-latitude aridification and wind patterns in the Asian interior. Geology, 2010, 38: $515-518$

38 Qiang X, An Z, Song Y, et al. New eolian red clay sequence on the western Chinese Loess Plateau linked to onset of Asian desertification about 25 Ma ago. Sci China-Earth Sci, 2011, 54: 136-144

39 Sun X, Wang P. How old is the Asian monsoon system? - Palaeobotanical records from China. Palaeogeogr Palaeoclimatol Palaeoecol, 2005, 222: 181-222

40 Shi Y F. Tang M C, Ma Y Z. Linkage between the second uplifting of the Qinghai-Xizang (Tibetan) Plateau and the initiation of the Asian monsoon system. Sci China Ser D-Earth Sci, 1999, 42: 303-312

41 Guo Z T, Sun B, Zhang Z S, et al. A major reorganization of Asian climate by the early Miocene. Clim Past, 2008, 4: 153-174

42 Tang H, Micheels A, Eronen J, et al. Regional climate model experiments to investigate the Asian monsoon in the Late Miocene. Clim Past, 2011, 7: 847-868

43 Shi Z, Liu X, An Z, et al. Simulated variations of eolian dust from inner Asian deserts at the mid-Pliocene, last glacial maximum, and present day: contributions from the regional tectonic uplift and global climate change. Clim Dyn, 2011, 37: 2289-2301

44 Zhang Z S, Wang $\mathrm{H}$, Guo Z, et al. What triggers the transition of palaeoenvironmental patterns in China, the Tibetan Plateau uplift or the Paratethys Sea retreat? Palaeogeogr Palaeoclimatol Palaeoecol, 2007, 245: 317-331

45 Chen L X, Liu J P, Zhou X J, et al. Impact of uplift of QinghaiXizang Plateau and change of land-ocean distribution on climate over Asia (in Chinese). Quat Sci, 1999, 4: 314-329

46 Yu Y Q, Zhou Z Y, Zhang X H. Impact of the closure of Indonesian seaway on climate: A numerical modeling study. Chin Sci Bull, 2003, 48: 88-93

47 Zhou B T, Zhao P, Jian Z M, et al. Modeling the impact of Australian Plate drift on Southern Hemisphere climate and environment. Chin Sci Bull, 2005, 50: 1495-1502

48 Quade J, Cerling T E, Bowman J R. Development of Asian monsoon revealed by marked ecological shift during the latest Miocene in northern Pakistan. Nature, 1989, 342: 163-166

49 Garzione C N, DeCelles P G, Hodkinson D G, et al. East-west extension and Miocene environmental change in the southern Tibetan Plateau: Thakkhola graben, central Nepal. Geol Soc Am Bull, 2003, 115: 3-20

50 Nakayama K, Ulak P D. Evolution of fluvial style in the Siwalik Group in the foothills of the Nepal Himalaya. Sediment Geol, 1999, 125: 205-224

51 Zheng H B, Powell C M, Rea D K, et al. Late Miocene and midPliocene enhancement of the East Asian monsoon as viewed from the land and sea. Glob Planet Change, 2004, 41: 147-155

52 Wang P X, Jian Z M, Zhao Q H, et al. South China Sea evolution and Deep Sea evidences of monsoon history (in Chinese). Chin Sci Bull (Chin Ver), 2003, 48: 2228-2239

53 An Z S, Zhang P Z, Wang E Q, et al. Changes of the monsoon-arid environment in China and growth of the Tibetan Plateau since the Miocene (in Chinese). Quat Sci, 2006, 26: 678-693

Open Access This article is distributed under the terms of the Creative Commons Attribution License which permits any use, distribution, and reproduction in any medium, provided the original author(s) and source are credited. 